\title{
Ontological Minimalism about Phenomenology
}

\author{
SUSANNA SCHELLENBERG
}

\section{The Australian National University}

\begin{abstract}
I develop a view of the common factor between subjectively indistinguishable perceptions and hallucinations that avoids analyzing experiences as involving awareness relations to abstract entities, sense-data, or any other peculiar entities. The main thesis is that hallucinating subjects employ concepts (or analogous nonconceptual structures), namely the very same concepts that in a subjectively indistinguishable perception are employed as a consequence of being related to external, mind-independent objects or property-instances. These concepts and nonconceptual structures are identified with modes of presentation types. Since a hallucinating subject is not related to any such objects or property-instances, the concepts she employs remain empty. I argue that the phenomenology of hallucinations and perceptions can be identified with employing concepts and analogous nonconceptual structures. By doing so, I defend an ontologically minimalist view of the phenomenology of experience that (1) vindicates Aristotelianism about types and (2) amounts to a naturalized view of the phenomenology of experience.
\end{abstract}

Galileo: Vision is perfect. People have very good eyes.

Aprcius: Whose weak eyes, then, need the help of your lenses?

GaLILEO: They are the eyes of the philosophers.

Fontenelle, Dialogues des morts, 1683

When a subject sees an object instantiating certain properties, it is natural to say that it seems to her that she is seeing an object instantiating those properties because she is perceptually related to that very object and those very property-instances. So when she sees a white cup, it seems to her that there is a white cup precisely because she is perceptually related to a white cup. By definition, 
when a subject is hallucinating, she is not perceptually related to the external, mind-independent object that her experience is seemingly of. If she is suffering a non-veridical hallucination, it seems to her that there is a particular object, such as a white cup, where in fact there is none. Since she is not perceptually related to a white cup, the fact that it seems to her that there is a white cup present cannot be explained in virtue of a perceptual relation to an external, mind-independent object and the properties it instantiates. So how should we explain the phenomenology of hallucinations? Let's call this the hallucination question. Many differences between philosophical views of perceptual experience can be traced back to how this question is answered.

There are two standard ways of answering the hallucination question. One common response is to argue that a hallucinating subject stands in an awareness relation to a peculiar entity. This peculiar entity has been understood to be an abstract entity, such as a property-cluster, an (uninstantiated) universal, an intentional object, or a proposition. It has also been understood to be a strange particular, such as a sensedatum, a quale, or a Meinongian object. ${ }^{1}$ As Dretske formulates the idea: "hallucinations are experiences in which one is aware of properties. ... Can we really be aware of (uninstantiated) universals? Yes, we can, and, yes, we sometimes are" (2000, p. 162-3). Similarly, Tye writes: "[i]n attending to the color of the ball, you are directly aware of

For views according to which hallucinating subjects stand in awareness or acquaintance relations to property-clusters, see Johnston 2004; for intentional objects, see Harman 1990, Lycan 1996; for propositions, see Russell 1913; for sense-data, see Robinson 1994; for qualia, see Block 2003; for Meinongian objects, see Parsons 1980. It is important to note that one could argue that hallucinating subjects represent intentional objects without arguing that the subjects stand in awareness or acquaintance relations to such objects. For a defense of such a view, see Crane 1998. Similarly, one can argue that the phenomenology of hallucinations is constituted by qualia without arguing that hallucinating subjects stand in awareness or acquaintance relations to these qualia. For a defense of such a view, see Chalmers 1996, McLaughlin 2007, and Shoemaker 2007. Finally, one can argue that the content of a hallucination is a Russellian proposition without arguing that hallucinating subjects stand in awareness or acquaintance relations to these propositions or their constituents. Byrne (2001) and Pautz (2007) defend versions of such a view. Arguably, any view that aims to explain phenomenology in virtue of properties or objects that constitute the content of experience is committed to positing that the experiencing subject stands in an awareness or acquaintance relation to these properties or objects. For a defense of this thesis, see Crane 2006, p. 128ff. It would lead too far afield to discuss here to what extent such views are peculiar entity views. I will reserve this for another occasion. For the purposes of this paper, any view that denies that subjects stand in awareness or acquaintance relations to peculiar entities is not my target. I will address such views only to the extent that they face the same problems as peculiar entity views. 
a certain quality, $Q$, as covering that surface. ... If the ball does not exist [you are hallucinating], still you are directly aware of $Q$... the phenomenal character involves the surface qualities of which the subject of the visual experience is directly aware" (2002, p. 141). With 'peculiar entity' I mean any object that is not an external, mind-independent object, such as a cat, cup, or a carrot; and any property that cannot be analyzed in terms of external, mind-independent propertyinstances, such as the whiteness or shape of the cup on my desk, or relations to such property-instances. Let's call a view according to which a hallucinating subject stands in an awareness relation to an entity that is not a material, mind-independent object or propertyinstance, a peculiar entity view. Peculiar entity views have it that since hallucinating subjects are aware of something, they must stand in an awareness relation to something that accounts for this phenomenology. So such views operate with a particular understanding of what it means to be aware of something. By distinguishing between extensional and intensional awareness, I will argue that one can acknowledge that hallucinating subjects are aware of something without analyzing "awareness of" in terms of an awareness relation to an object, property, or any other entity.

A second way of responding to the hallucination question is to stipulate that a hallucination could be subjectively indistinguishable from a perception, but to leave unexplained how this could be possible (e.g. Snowdon 1981, Campbell 2002). ${ }^{2}$ Let's call such a view negativism about hallucinations. Negativist views avoid introducing peculiar entities of which hallucinating subjects are aware, but at the cost of leaving unexplained just what accounts for the phenomenology of hallucinations and how a hallucination could be subjectively indistinguishable from a perception.

There are many ways of understanding the claim that two experiences are subjectively indistinguishable. Williamson (1990) uses the expression to pick out an epistemic notion. In short, the idea is that two experiences $e_{1}$ and $e_{2}$ are subjectively indistinguishable for a subject if and only if she is not able to know by introspection alone that $e_{1}$ and $e_{2}$ are not the same. I will follow this use. I will not argue here that the possible subjective indistinguishability of a hallucination and a perception needs to be explained. In the context of this paper, I will

Of course, it need not be a positive part of the view that the possible subjective indistinguishability of a hallucination and a perception is not something that requires explanation. What characterizes negativism is the fact that the view does not explain possible subjective indistinguishability. Negativist views could fail to explain this due to neglect or since the defender of the view holds that possible subjective indistinguishability is something that does not require explanation. 
take this for granted. Indeed, I will posit that any account of experience should explain the possibility that a perception and a hallucination can (seemingly) have the same phenomenology and thus be subjectively indistinguishable. ${ }^{3}$ Call this the indistinguishability desideratum.

The distinction between the way the peculiar entity view and negativism answer the hallucination question is orthogonal to the distinction between two fundamentally different ways of thinking about the relation between hallucinations and accurate perceptions. Disjunctivists and naive realists characterize hallucinations in terms of a deficiency of an accurate perception and argue that perceptions and hallucinations do not share a common element. ${ }^{4}$ By contrast, common factor views have it that perceptions and subjectively indistinguishable hallucinations share a common element that accounts for the phenomenology of the experiences. Although the two distinctions are orthogonal, most peculiar entity views are common factor views and most negativist views are versions of disjunctivism. The fault line between disjunctivism and common factor views does not however coincide with the fault line between negativism and peculiar entity views. There are for instance views on which hallucinations - but not perceptions - are a matter of being related to a peculiar entity (e.g. Johnston 2004). So there are peculiar entity views on which hallucinations and perceptions do not share a common element. However, with the aim of giving a common account of both perception and hallucination, most peculiar entities views posit that a perceiving subject is related to the very same (or the very same kind of) peculiar entity that she would be related to, were she hallucinating.

My aim is to present a positive view of hallucinations that satisfies the indistinguishability desideratum without endorsing the thesis that perceptions or hallucinations are a matter of standing in an awareness relation to a peculiar entity. I will pursue this aim by arguing that perceptions and subjectively indistinguishable hallucinations share a common element that accounts for the subjective indistinguishability of the

3 It should be noted that Campbell (2002) denies that a hallucination has the same phenomenology as a perception in the metaphysical sense. However, even he concedes that a hallucination could be subjectively indistinguishable from a perception in the epistemic sense, given that the experiencing subject may not be able to tell that there is a metaphysical difference between her experiences.

4 Naïve realism is a new-fangled version of disjunctivism. By contrast to most traditional disjunctivists, naïve realists deny not only that hallucinations have content, but are moreover skeptical that perceptions have content. Campbell (2002), Travis (2004), and Brewer (2006) argue explicitly that perceptions do not have content. For ease of presentation, I will speak only of disjunctivism, but everything I say about disjunctivism generalizes to naïve realism. 
experiences, while acknowledging that hallucinations exhibit a deficiency that can only be explained with reference to accurate perceptions. So I will defend a common factor view that does not amount to a peculiar entity view and that recognizes the disjunctivist insight that hallucinations are deficient. The main thesis is that hallucinating subjects employ concepts (or analogous nonconceptual structures), namely the very same concepts that in a subjectively indistinguishable perception are employed as a consequence of the perceiving subject being related to external, mind-independent objects and property-instances. Since a subject who suffers a non-veridical hallucination is not perceptually related to the external, mind-independent objects or propertyinstances that it seems to her are present, the concepts she employs remain empty. As a consequence, hallucinations are deficient. Insofar as the concepts employed in hallucinations are grounded in perceptions and can only be analyzed with regard to their role in perceptions, hallucinations are derivative of perceptions.

In $\S 1$, I will critically discuss disjunctivism and those versions of the common factor view on which experiential states are awareness relations to peculiar entities. In $\$ 2$, I will develop a view of the phenomenology of experience that circumvents the need to think of experiences in terms of awareness relations to peculiar entities. I will call it ontological minimalism about phenomenology. In \$3, I will discuss the notion of content that this view implies. In $\$ 4$, I will respond to five objections to the view.

First, it is necessary to make a few terminological remarks. When I speak of an experience without qualification, I mean an experience that is a perception, a hallucination, or an illusion. When I speak of objects without further qualifications, I mean material, mind-independent objects, such as cats, cups, or carrots.

\section{Disjunctivism and the Common Factor View}

Disjunctivists take as their starting point the perceptual relation between subject and object in the case of an accurate perception and argue that perception is fundamentally a perceptual relation to an object. When a subject $s$ perceives an object $o$, she stands in a perceptual relation $R$ to that very object $o$. So perception has the form Rso. Since a hallucinating subject is not perceptually related to an object, or at least not the one that it seems to her she is related to, a hallucination could not possibly share the $R s o$-form of perception. So disjunctivists conceive of the structure of perception in a way that a hallucination could not possibly share. As a result they argue that there is no common element between hallucinations and perceptions. 
There are at least two problems with such a view that are of immediate relevance for present purposes. A first problem is that if phenomenology is explained in terms of perceptual relations to the very objects that the experiencing subject sees and the properties that this object instantiates, then it is unclear what accounts for the phenomenology of hallucinations. A hallucinating subject is not perceptually related to the object that it seems to her is present. So the phenomenology of her experience cannot be explained simply in terms of perceptual relations to objects and the properties they instantiate. A second problem is that, if the fundamental structure of perception is one that a hallucination could not possible share, then it is unclear how the indistinguishability desideratum could be satisfied. ${ }^{5}$ Obviously, there is much more to be said about these problems. I cannot here do justice to the subtleties of disjunctivism. ${ }^{6}$ Rather than further pursue a discussion of disjunctivism, I will assume that these two problems are problems and focus on developing a view that avoids them without positing that hallucinating subjects are aware of peculiar entities.

In contrast to disjunctivism, common factor views argue that there is a common element between perceptions and subjectively indistinguishable hallucinations. There are many different versions of this view. Indeed there are at least as many different versions as there are different ways of conceiving of the common element, multiplied by the different possible ways of understanding the additional element that distinguishes hallucinations from perceptions. Adverbialism has it that being appeared to F-ly is the common element between perceiving and hallucinating an $F$ (Chisholm 1957). Adverbialism is a view according to which hallucinations and perceptions share a common element, without that common element constituting a peculiar entity. On sensedatum theory, the common element is a sense-datum, that is, a concrete particular that has just the properties of which the experiencing subject is aware (Price 1950, Moore 1953, Jackson 1977, Robinson 1994). Qualia theory argues that the common element is a quale (e.g. Block 1990, Chalmers 1996). All three views have been criticized widely (e.g.

Martin (2002) argues that a hallucination that is subjectively indistinguishable from a perception instantiates an indistinguishability property in virtue of which it is subjectively indistinguishable from the perception. More specifically, he argues that our epistemic situation with regard to our experience is the same regardless of whether we are perceiving or hallucinating. Arguably, this does not constitute an explanation of what accounts for the hallucination being subjectively indistinguishable and so such an account does not satisfy what we have called the indistinguishability desideratum. For a discussion of Martin's indistinguishability properties, see Siegel 2004.

6 For detailed discussions, see Haddock and Macpherson 2008, Siegel 2008, and my forthcoming-a. 
Strawson 1979, Smith 2002, Johnston 2004, Crane 2006) and I have nothing substantial to add to their criticisms. I will focus on those versions of the peculiar entity view on which the experiencing subject stands in an awareness relation to an abstract entity. In particular, I will concentrate on property-cluster views.

According to the property-cluster view an experiencing subject is related to a property-cluster regardless of whether she is perceiving or hallucinating. There are at least three versions of this view. On what I will call a pure property-cluster view, experience does not have content. It is simply a matter of being related to a propertycluster. On what I will call a content property-cluster view, experience is a matter of being related to a Russellian proposition that is constituted by a property-cluster and possibly one or more objects. There are two versions of the content property-cluster view. On the standard view, perceptions and subjectively indistinguishable hallucinations are analyzed in terms of relations to the very same (or the very same kind of) Russellian proposition. On a gappy version of the view, the content of a hallucination is gappy in the object-place because an object is missing, while the gap is filled by an object in the case of a perception. ${ }^{7}$

Not all of these views rely on awareness relations to abstract objects. However, as I will argue shortly, any property-cluster view requires that the property-cluster is potentially constituted by uninstantiated universals to avoid facing obvious counterexamples. In the rest of this section, I will present an argument against those versions of the common factor view according to which hallucinating subjects stand in an awareness relation to an abstract entity. I will focus first on the pure property-cluster view and will then discuss the extent to which the problems facing this view arise for content property-cluster views.

Since the property-cluster view is most famously associated with Johnston, it will be helpful to make a few clarifying remarks about his account to begin. Johnston's view is summed up in the following passage:

When we see we are aware of instantiations of sensible profiles. When we hallucinate we are aware merely of the structured qualitative parts of such sensible profiles. Any case of

The pure property-cluster view is defended by Johnston (2004); for the content property-cluster view, see Tye 2000, Byrne 2001, and Pautz 2007 among others; for the gappy content property-cluster view, see Bach 2007 and Tye 2007. I defend a gappy content view (see my 2006), but one that is not a version of the propertycluster view. 
hallucination is thus a case of "direct" visual awareness of less than one would be "directly" aware of in the corresponding case of seeing. (2004, p. 137)

As Johnston argues, when we hallucinate, we are aware of an uninstantiated property-cluster, that is, a structured qualitative part of a sensible profile. When we perceive, we are aware of a property-cluster instantiated by an external, mind-independent object, that is, an instantiated sensible profile. Instantiations of sensible profiles and structured qualitative parts of sensible profiles are not the same things. Given that they are not the same things, there is no reason to think that they amount to a common factor. If they do not amount to a common factor, then Johnston's view is a version of disjunctivism. ${ }^{8}$ For the sake of clarity, I will work with an idealized version of a property-cluster view on which a hallucinating subject is related to the very same propertycluster regardless of whether she is hallucinating or perceiving. Everything I will say about the idealized version generalizes to versions of the property-cluster view on which there are differences between what the subject is related to when she is hallucinating and what she is related to when she is perceiving. So everything I will say about the idealized version generalizes to Johnston's property-cluster view.

Consider a subject $s$ who has a non-veridical hallucination as of a material, mind-independent object $o$ that seems to be instantiating property $P$ at location $L$. Since there is no object $o$ at location $L$, there is no object that could be instantiating $P$. Therefore, what the subject is aware of can neither be the material, mind-independent object $o$, nor the properties instantiated by such a material, mind-independent object. The property-cluster view has it that hallucinating subjects stand in an awareness relation to properties that are not instantiated where the subject experiences them to be instantiated. Since these properties are not instantiated where they are experienced to be, they are conceived of as universals. This view is phenomenologically controversial since universals are abstract entities. Abstract entities are not spatially extended and it is not clear what it would be to be sensorily aware of something that is not spatially extended. ${ }^{9}$ At least phenomenally, it is more plausible to say that when one experiences a white cup, one is aware of an instance of whiteness, not an abstract entity. ${ }^{10}$

\footnotetext{
8 For a critical discussion of Johnston's view along these lines, see also Pautz 2007.

9 A second way that one may question the possibility of sensory awareness of abstract entities is by arguing that such awareness requires causation and universals do not cause. For an excellent discussion of the problem of sensory awareness of abstract entities and possible solutions to it, see Pautz 2007.

For a classical defense of this thesis, see Williams 1953.
} 
There are several possible ways for the property-cluster theorist to respond to the criticism that the view is phenomenologically controversial. She might distinguish between being sensorily and cognitively aware of something. This would allow her to argue that hallucinating subjects are cognitively aware of abstract entities, while perceiving subjects are sensorily aware of the objects and property-instances to which they are perceptually related. Even if we would grant, for the sake of argument, that one could be cognitively aware of abstract entities, this response to the phenomenological worry raised above faces a second phenomenological problem. Arguably, being cognitively aware of something is phenomenally distinct from being sensorily aware of something. If this is right, then it is not clear how such an approach would satisfy the indistinguishability desideratum.

The property-cluster view could circumvent this second phenomenological problem by arguing that subjects are cognitively aware of abstract entities regardless of whether they are perceiving or hallucinating. This way of dealing with the problem faces several worries. One worry is that perceptual experience is assimilated too strongly to thought. A second worry is that while non-rational animals can perceive, it is not clear that they can be cognitively aware of abstract entities. A third worry is how such a view can account for the particular sensory character of experiences. There are several options for the property-cluster theorist to proceed from this point. But any option will involve positing that hallucinating subjects are either cognitively or sensorily aware of abstract entities. Arguably, this is reason enough to be at the very least wary of the view.

The property-cluster view is not only phenomenologically controversial, it is moreover metaphysically controversial. To show why, let's assume for a moment an Aristotelian view of types, that is, a view that is committed to the principle that the existence of a type depends on its tokens, where the tokens depend in turn on concrete entities of the physical world insofar as the tokens are for instance instantiated by concrete physical entities. We can call this the Aristotelian principle. This principle implies that any type must be tokened somewhere and that it must be possible to analyze any token in terms of concrete entities of the physical world. Applied to properties, the Aristotelian principle implies that any property must be instantiated somewhere.

A property-cluster theorist who accepts the Aristotelian principle will have to constrain possible hallucinations to hallucinations of properties that are instantiated somewhere in the actual world. But by doing so her view faces a whole range of counterexamples. It is 
easy to conceive of hallucinations of uninstantiated properties, that is, properties that are not instantiated anywhere. Examples are hallucinations of Hume's missing shade of blue and hallucinations of supersaturated red. Not only are such hallucinations conceivable, they are easy to produce. ${ }^{11}$

The property-cluster theorist could account for hallucinations of uninstantiated properties by rejecting the Aristotelian principle and by arguing that hallucinating subjects are at least sometimes related to uninstantiated universals. ${ }^{12}$ However by doing so, she commits herself to a controversial metaphysical view of types. The view is metaphysically controversial since accepting the existence of uninstantiated universals requires some kind of Platonic 'two realms'-view on which there is more to reality than what can be analyzed in terms of what exists in the concrete physical world. There are universals that cannot be analyzed in terms of their instances in the concrete physical world or in terms of any other concrete physical entities. The rival Aristotelian view that requires universals to be analyzable in terms of concrete physical entities can do without such a Platonic heaven. By understanding abstract entities such as universals in terms of their instances, the Aristotelian view can accept the existence of abstract entities, while denying that subjects are ever aware of anything other than the instances of these abstract entities. ${ }^{13}$

See Ffytche and Howard (1999) and Ffytche (2008).

When I speak of an uninstantiated universal, I mean - following common use-a universal that is not instantiated anywhere. It is important to distinguish an uninstantiated universals from a universal that is instantiated somewhere, but not instantiated where a subject who suffers an illusion or hallucination experiences it to be instantiated.

For a critical discussion of uninstantiated universals, see Armstrong 1989. Armstrong restricts the Aristotelian principle to so-called sparse properties. By contrast, I aim to vindicate the Aristotelian principle for all perceivable properties. One might object that the metaphysical problem articulated over-generalizes in that it would work just as well against Russellian accounts of the content of false beliefs. The metaphysical problem articulated is specific to accounts of perceptual experience that analyze experience in terms of awareness relations to (uninstantiated) abstract entities. If experience is analyzed in terms of awareness relations to (uninstantiated) abstract entities, then these (uninstantiated) abstract entities must exist such that we could stand in an awareness relation to them. The same is not true of beliefs of abstract entities, since there is no reason why a belief as of $o$ must be analyzed in terms of an awareness relation to $o$. If however beliefs are analyzed in terms of awareness relations to (uninstantiated) abstract entities, then the phenomenological and metaphysical problems articulated would indeed arise for such an account of beliefs. Thanks to Nico Silins for pressing me on this point. As I will show in the next section, any view that analyzes the phenomenology of perceptual experience in terms of an awareness relation to (uninstantiated) abstract entities should and can be avoided. 
To what extent does the content property-cluster view inherit the problems of the pure property-cluster view? Any view on which the content of experience is constituted by naked properties and objects inherits the metaphysical problem of the pure property-cluster view. For the gappy content property-cluster view, this problem manifests itself in the following way. Let's assume again for a moment the Aristotelian principle. Given this assumption, the defender of this view faces an unfortunate choice point. (i) He can deny that hallucinations of uninstantiated properties are possible. This first strategy faces the counterexamples of hallucinations of uninstantiated properties such as supersaturated red. (ii) Alternatively, he can accept that hallucinations of such properties are possible and argue that they have the content $<\ldots, \ldots$. The content is gappy in both the object and property-place since the subject neither stands in an awareness relation to any mindindependent object nor any properties. This second strategy implies that any hallucination of uninstantiated properties will have the very same content. So a hallucination of supersaturated red will have the very same content as a hallucination of Hume's missing shade of blue. If the content of experience is supposed to ground the phenomenology of the relevant experience, then such a view of content will predict that a hallucination of supersaturated red will have the very same phenomenology as a hallucination of Hume's missing shade of blue. So the gappy content property-cluster view must reject the Aristotelian principle to avoid either (i) denying that hallucinations of uninstantiated properties are impossible or (ii) positing experiential contents that do not have sufficient structure to account for phenomenal differences between hallucinations of uninstantiated properties.

More generally, any content property-cluster view is committed to accepting the existence of uninstantiated universals to avoid restricting possible hallucinations to hallucinations of properties that are instantiated somewhere. So since such a view is committed to rejecting the Aristotelian principle and accepting a Platonic 'two realms'-view, it inherits the metaphysical problem of the pure property-cluster view. For the reasons given above, I take this problem to be sufficient to reject any such view in favor of a view that can accommodate with the Aristotelian principle.

Does the content property-cluster view inherit the phenomenological problems of the pure property-cluster view as well? The answer to this question depends on how one understands the relation between the experiencing subject and the content of her experience. Russell argued that subjects stand in acquaintance relations to the objects and properties that constitute propositions. He used the terms "acquaintance" and "awareness" synonymously (1913, p. 35), and indeed the standard 
reading of Russell has it that his acquaintance relations are a particular kind of awareness relations. ${ }^{14}$ If we stand in awareness relations to the properties and objects that constitute the content of our experience, then the Russellian view inherits all the phenomenological problems of pure property-cluster views. Such a view is committed to the phenomenologically controversial thesis that hallucinating subjects are either sensorily or cognitively aware of abstract entities. ${ }^{15}$ Byrne (2001) and Pautz (2007) argue that the content of experience is a Russellian proposition, but deny that experiencing subjects stand in acquaintance or awareness relations to this proposition or its constituents. If this approach works, then such a view inherits only the metaphysical problem of the pure property-cluster view and not its phenomenological problems.

\section{Ontological Minimalism about Phenomenology}

So far I have articulated the problems of disjunctivism and any view according to which perceptions or hallucinations are a matter of standing in an awareness relation to abstract entities. In the rest of this paper, I will present an account of phenomenology that avoids positing that subjects are aware of abstract entities or any other peculiar entities. The problems of peculiar entity views are avoided, if hallucinating subjects are understood not as related to abstract entities, but rather as employing concepts (or analogous nonconceptual structures), where concepts take objects, property-instances, or other external, mind-independent entities as inputs and yield contents as outputs. ${ }^{16}$ As I will

14 For a recent interpretation of Russell's acquaintance relations along these lines, see Campbell 2009.

15 For views that are committed to the thesis that subjects are either sensorily or cognitively aware of abstract entities, such as (uninstantiated) universals, propositions or their constituents, see McGinn 1982, Harman 1990, Davies 1992, Lycan 1996, Dretske 2000, and Tye 2002. It is important to note that such views are not committed to the thesis that we are aware of abstract entities or any other peculiar entities as such.

16 The idea that concepts take objects, property-instances, or other external, mindindependent entities as inputs and yield contents as outputs can be interpreted functionally. In formal discussion, functions are understood as necessarily requiring an input to have an output. As I am understanding concepts, one can employ a concept and thereby be in a mental state with content, despite the fact that one is not perceptually related to anything. So one can employ a concept and yield a content as output even if there is no input. So if the idea that concepts take objects or property-instances as inputs and yield contents as outputs is interpreted functionally, then it is important to note that the notion of function in play is distinct from the one in formal discussion. Alternatively, the view presented here could be reformulated by arguing that in the case of a hallucination, the input is the empty set. This would allow being in tune with the use of "functions" in formal discussions, but would require accepting the existence of the empty set. 
show in the next section, these concepts correspond to mode of presentation types. The notion of property-instances in play is best illustrated with an example: when one sees two qualitatively identical white cups, the cups instantiate the same property, but the instances are distinct. When one suffers a hallucination as of a white cup, it seems to one that there is a white cup present, but since one is not perceptually related to the object that it seems to one is present, one is not perceptually related to any instance of whiteness. As I will argue, possessing a concept grounds the ability to refer to external, mind-independent objects or property-instances. For the sake of definiteness, I will focus on the case in which experience is a matter of employing concepts, but everything I say can be reformulated in terms of nonconceptual structures rather than concepts. Given the notion of concepts in use, it is unproblematic to attribute basic concepts to non-rational animals. However, even if this notion of concepts is compatible with attributing basic concepts to non-rational animals, it is plausible that perceptual content is constituted at least in part nonconceptually.

On the view I am suggesting, the content of experience is not constituted by naked objects and properties as on the property-cluster view and most other peculiar entity views. Rather the content of experience is constituted by modes of presentations of objects and properties. More specifically, the content ensues from employing concepts that pick out objects and property-instances. When a subject hallucinates, the concepts that she employs are empty. When a subject perceives, objects or property-instances are subsumed under the concepts employed: the objects to which she is perceptually related are subsumed under the employed object-concepts; the property-instances to which she is perceptually related are subsumed under the employed propertyconcepts. The common element between hallucinations and perceptions is constituted by the concepts that the subject employs in a sensory mode regardless of whether she is hallucinating or perceiving. The relevant sensory modes are modes such as seeing, hearing, touching, smelling, or tasting.

How can such a view explain the phenomenology of hallucinations? I will argue that employing concepts and analogous nonconceptual structures in a sensory mode grounds the phenomenology of experience. So any experience in which the same concepts are employed in the same mode will have the same phenomenology. Given this constraint there are two ways of understanding the relation between the phenomenology and the employed concepts. One could identify the phenomenology of experience with employing concepts and analogous nonconceptual structures in a sensory mode. Alternatively, the phenomenology can be argued to supervene on employing concepts and 
analogous nonconceptual structures in a sensory mode. I will argue for the identity thesis, but my argument needs to be modified only slightly to be compatible with the weaker supervenience thesis. On both versions of the view, whether or not a concept is empty will not affect the phenomenology of the experience. Only if this is the case, can the view satisfy the indistinguishability desideratum. For only if it is not revealed in phenomenology whether a concept is empty or not can a perception and a hallucination be subjectively indistinguishable.

Let's call such a view ontological minimalism about phenomenology, or minimalism for short. The view is ontologically minimalist since it accounts for the phenomenology of perceptual experience without having to appeal to awareness of peculiar entities and since it vindicates the Aristotelian principle in ways that I will explain in the rest of this section. By rejecting the Russellian thesis that content is constituted by naked objects and properties in favor of the thesis that content ensues from employing concepts that pick out objects and property-instances, minimalism about phenomenology entails a Fregean view of content. While minimalism appeals to concepts employed in experience and thus appeals to abstract entities, I will argue that experiencing subjects do not stand in an awareness relation to these abstract entities. On the notion of concepts in play, concepts are understood in terms of their tokens, which in turn are analyzed in terms of the very mind-independent objects and property-instances that we are perceptually related to when we perceive.

The suggested way of thinking about experience makes it possible to acknowledge that a hallucinating subject does not stand in an awareness relation to anything despite enjoying a phenomenology that purports to be of mind-independent objects and property-instances. To defend the conjunction of these two theses it will be helpful to uncover an ambiguity in the notion of "awareness of". On one understanding, for a subject to be aware of something means that the subject stands in an awareness relation to that very object or property. This notion of "awareness of" implies that a subject cannot be aware of something without standing in an awareness relation to that very thing. Call this extensional awareness. Peculiar entity views take "awareness of" to imply extensional awareness. If "awareness of" were necessarily extensional awareness, then a hallucinating subject must be standing in an awareness relation to some object or property. Since she is by definition not related to an external, mind-independent object and the properties this object instantiates, such as a white cup, the object in question must be a peculiar entity.

If we recognize that there is a second way of understanding "awareness of" this conclusion can be avoided. On a second understanding, 
for a subject to be aware of something means only that the subject is in a mental state that purports to be of something. This understanding of "awareness of" allows that a subject can be aware of something without standing in an awareness relation to any relevant thing. So on this understanding, being aware of something does not entail the existence of what she is aware of. Call this intensional awareness. In this intensional sense, one can be aware of ghosts.

Another way to bring the distinction between the two notions of "awareness of" into focus is to center on the grammatical structure of experiential reports. Denying that hallucinating subjects stand in awareness relations to an object is not to deny the linguistic fact that the expression "I hallucinate" takes a grammatical object. The important thing to recognize is that this grammatical object does not correspond to an ontological existent to which the hallucinating subject stands in an awareness relation. It merely marks what the hallucinating subjects takes to be present and what she would be perceptually related to, were she perceiving an external, mind-independent object.

The distinction between extensional and intensional awareness is analogous to the distinction between relational and phenomenological particularity. ${ }^{17}$ A mental state instantiates relational particularity if and only if the experiencing subject is perceptually related to the particular object perceived. A mental state instantiates phenomenological particularity only if it (perceptually) seems to the subject as if there is a particular object present. More generally, a mental state instantiates phenomenological particularity only if the particularity is in the scope of how things seem to the subject. Every experience exhibits phenomenological particularity. Indeed it is unclear what it would be to have an experience that seems to be of an external, mind-independent object without it seeming to the subject that there is a particular object present. If a subject has an experience that is intentionally directed at a particular object it will seem to her as if she is experiencing a particular object-regardless of whether there is in fact an object present. If this is right, then any view on which experience is object-directed is committed to saying that perceptual experience exhibits phenomenological particularity. When one hallucinates it seems to one as if one is perceiving a particular object - at least if the hallucination is phenomenally indistinguishable from a perception. So hallucinations instantiate phenomenological particularity. Since hallucinating subjects are not related to a mind-independent object, hallucinations do not instantiate relational particularity.

17 For a defense of the distinction between relational and phenomenological particularity, see my 2010. 
While the distinction between extensional and intensional awareness is analogous to the distinction between relational and phenomenological particularity, it is however important to note that they pertain to different sets of issues. Extensional and intensional awareness both concern the phenomenology of experience. By contrast, whether a mental state instantiates relational particularity is, I argue, not revealed in the phenomenology of the experience.

Recognizing the distinction between extensional and intensional awareness makes it possible to accept the Aristotelian principle without forfeiting a positive account of hallucinations. So it makes it possible to understand properties in terms of their instances, but nonetheless give a positive account of the phenomenology of hallucinations. The entities that a subject stands in an awareness relation to are always either material, mind-independent objects such as cats and chairs, the properties that these objects instantiate, or a combination of propertyinstances and objects. So according to minimalism, subjects are only ever extensionally aware of mind-independent, external objects, property-instances, or other concrete mind-independent entities.

Now, one may wonder how such an account can secure the identity of hallucinated objects across hallucinations. It cannot, but this is a desirable consequence of the view. A hallucinating subject may form false judgments on the basis of her hallucinations and believe that the unicorn it seemed to her she was seeing yesterday is the very same unicorn as the one that it seems to her she is seeing today. But the identity postulated here is within the scope of how things seem to the subject and thus based on mere phenomenological particularity. There is nothing in the world that corresponds to how things seem to the subject. So there is nothing in the world that corresponds to this phenomenological particularity. In other words, the phenomenological particularity of her experience is not matched with any relational particularity. Since the subject is not standing in an awareness relation to any unicorns, no identity of the hallucinated objects can be secured.

So far I have specified concepts roughly as taking objects, propertyinstances, or other external, mind-independent entities as inputs and yielding contents as outputs. If concepts are understood in terms of what they refer to or what they pick out, then the question arises of how minimalism can account for experiences of uninstantiated properties. In order to address this question, it is necessary to get a clearer understanding of the notion of concepts. On the notion in play, concepts cannot be analyzed independently of analyzing what it means to possess a concept. Possessing a concept grounds the ability to refer to the external, mind-independent objects or property-instances that the 
concept is of. ${ }^{18}$ This ability involves among other things being able to discriminate between the things that fall under the concept and those that do not. ${ }^{19}$ So a subject who possesses the concept of redness must be able to use it to refer to red things, which involves discriminating red things from things that are not red. The ability to refer to objects and property-instances may be analyzed as constituting a kind of know-how, but one that should not be understood as over-intellectualizing the requirement for concept-possession. Following Ryle (1949), I am using 'know-how' to refer to a practical, non-intellectual conception that non-rational beings could have. ${ }^{20}$

To avoid terminological confusion, the notion of concepts in play must be distinguished from any notion on which concepts are mental representations (Fodor 1975, 1998, Jackendoff 1987, Lawrence and Margolis 1999, Carruthers 2000, Prinz 2002) or prototypes (Rosch 1978, Smith and Medin 1981), as well as any view according to which concepts are properties.

The thesis that concepts cannot be analyzed independently of their possession conditions does not entail that concepts are behaviorally reduced. The thesis does not even entail that one needs to successfully apply a concept to count as possessing the concept. The thesis is rather that one needs to have the ability to successfully apply a concept to count as possessing the concept. One may possess a concept, but not be in an environment that contains the objects and property-instances that fall under the concept and therefore not be able to successfully apply the concept. Moreover, as I will argue, one may never have been in an environment that contains the objects and property-instances that fall under the concept and nonetheless possess the concept that grounds the ability to refer to such objects and property-instances. So concepts ground the ability to refer to mind-independent objects and property-instances irrespective of whether these objects and property-instances are in fact present in the environment of the experiencing subject. If one employs a concept, in an environment in which no relevant objects and property-instances are

18 For a detailed discussion of concepts as analyzed in terms of their possession conditions, which in turn are analyzed in terms of abilities, see Peacocke 1992 and Sosa 1993.

19 It would lead too far afield to discuss here just what the conditions are for counting as being able to discriminate. For discussion of the capacity to discriminate, see McLaughlin 1996.

20

Ryle's conception of know-how has been famously criticized by Carr (1979) and more recently by Stanley and Williamson (2001). In short, the criticism is that 'know-how' expresses the same relation as 'know-that'. Addressing this criticism would only affect the wording of my argument. For a critical discussion of Stanley and Williamson's argument and a defense of a concept of know-how, see Hornsby 2004. 
present, then one fails to refer to what the concept purports to pick out. If one fails to refer, then the concept employed remains empty.

This way of thinking about concepts is closely related to two prominent views, so it will be helpful to contrast it with those views. It is closely related to Frege's understanding of concepts (Begriffe), but while Frege argues that concepts are functions from objects to truth-values, I am understanding concepts as taking objects, property-instances, or other external, mind-independent entities as inputs and yielding contents as outputs. The idea in play is particularly closely related to Peacocke's (1992) influential view of concepts. ${ }^{21}$ But while Peacocke argues that concepts are Fregean senses, I am thinking of the output of concepts as Fregean senses. On the way I am understanding the term, concepts themselves are not content tokens. ${ }^{22}$ Following both Frege and Peacocke, I am understanding concepts as abstract entities, rather than as psychological entities. Although concepts are abstract entities, I will argue that any given concept is necessarily employed at some point. Insofar as employing a concept tokens the concept and these tokens can in turn be analyzed in terms of the very objects and property-instances that the concept is of, accepting the suggested notion of concepts is compatible with accepting the Aristotelian principle that the existence of a type depends on its tokens, which depend in turn on concrete entities of the physical world. Thus any commitment to a Platonic 'two realms'-view can be avoided.

There are several possible ways of analyzing concepts, given the articulated constraints. On the understanding of concepts in play, conncepts could be analyzed in terms of conceptual roles as long as these conceptual roles are 'long-armed' (Block 1986, p. 636), that is, as long as they include relations to the world. ${ }^{23}$ By building on causal approaches (Kripke 1972/1980, Putnam 1975, Burge 1979, Devitt 1981), they could alternatively be analyzed in terms of mere relations to the world without any appeal to relations to other concepts. For the purposes of this paper, we can remain neutral on this issue. The important point is that possessing a concept grounds the ability to refer to objects or property-instances in the world.

I should not leave the impression that the content of experience is conceptually structured. As stated earlier, my argument does not

See also Sosa 1993.

Depending on how one understands contents, this may be a mere terminological difference. Peacocke could be read as equating concepts with mode of presentation types. This is just the understanding of concepts that I will argue for in $\S 3$. While concepts are mode of presentation types, the output of a concept is a mode of presentation token. 1993, and Brandom 1994. 
depend on experiential content being exclusively conceptually structured. There are powerful reasons to think that the content of experience is at least in part nonconceptually structured. Moreover, even if content is conceptually structured, this is compatible with understanding the state of experience as nonconceptual in that the experiencing subject does not have the cognitive tools to articulate the conceptually structured content of her experience. ${ }^{24}$

Now, how should we understand the relation between the content of perception and the content of hallucination on the suggested view? More specifically, how should we understand the relation between being perceptually related to external physical entities, such as white cups, and employing concepts that purport to be of such entities? In order to address this question, it will be necessary first to distinguish two possible versions of minimalism. On one version, perceptions of property-instances are necessary to acquire the concept that grounds the ability to have hallucinations that are intensionally of such property-instances. Similarly, perceptions of objects are necessary to acquire the concept that grounds the ability to have hallucinations as of objects of the same type. Let's call this view grounded minimalism. This version of minimalism posits that the content of hallucination is derivative of the content of perception either insofar as it ensues from reemploying and possibly recombining the concepts acquired in past perceptions or insofar as the concepts employed in hallucinations are extrapolations of concepts acquired in past perceptions.

On a second version of minimalism, hallucinations of properties or objects are possible even if one has not had past perceptions of instances of the same property or the same type of object. So this version of the view does not require that the concepts employed in hallucinations be acquired through perceptions. It allows that one can possess concepts without having been perceptually related to the objects or property-instances that the concept picks out. Let's call this view ungrounded minimalism. This version of minimalism allows that a subject could have a hallucination as of, say, an object unlike anything she has seen before. On a radical version of ungrounded minimalism, having a hallucination is sufficient to acquire the ability to refer to external, mind-independent objects and property-instances. ${ }^{25}$ The radical

\footnotetext{
24 For a defense of the distinction between content and state (non)conceptualism, see Heck 2000.

25 Pautz (forthcoming) argues that through hallucinations subjects can acquire the capacity to have beliefs that involve properties. As he understands it, the capacity to have beliefs that involve properties does not imply that subjects have the capacity to refer or pick out these properties and so does not amount to a version of what I am calling radical ungrounded minimalism.
} 
version is only plausible on the assumption that hallucinations of objects and property-instances (to which one has never been perceptually related) do not involve at least imagining such objects or propertyinstances, where imagination involves more high-level mental capacities than mere hallucination. On a modest version, the concepts employed in hallucinations are acquired through testimony or imagination. If perceptual concepts are understood to be grounded in accurate perceptions, then only the modest version can be plausible. For only if some bridge exists between my hallucination of a property that I have never seen and someone else's perception of an instance of this property, can the concept I employ in hallucination be plausibly understood to be grounded in accurate perceptions. We can remain neutral here on whether or not ungrounded minimalism is best understood in its radical or modest version. The important point for the discussion is that on both versions of ungrounded minimalism, a subject need not have had perceptions of objects and property-instances to have hallucinations as of such objects and property-instances. So ungrounded minimalism posits that a brain in a vat could have hallucinations as of white cups. ${ }^{26}$ On both the grounded and the ungrounded versions of minimalism, hallucinations are externally directed without involving awareness relations to abstract entities, sense-data, or any other peculiar entities.

The grounded and the ungrounded versions of minimalism both face problems if they are taken independently. Taken independently, grounded minimalism faces the problem that one can only have hallucinations of objects and property-instances if one has had perceptions of objects and property-instances that are sufficiently similar that one could successfully extrapolate from these experiences. Taken independently, ungrounded minimalism faces the problem that accounting for hallucinations as of objects or property-instances that are not sufficiently similar to one that the relevant subject has perceived requires rejecting the Aristotelian principle. Both problems are avoided if it is recognized that an analysis of what grounds our abilities to refer to objects and property-instances requires combining the two views. I will argue that grounded minimalism holds globally, but that ungrounded minimalism holds locally. vat could have such hallucinations, while modest ungrounded minimalism has it that a brain in a vat could only have hallucinations as of objects and propertyinstances, if the brain has acquired the relevant concepts from subjects who have perceived sufficiently similar objects and property-instances. If it is not possible for brains in vats to acquire concepts in such a way, then modest ungrounded minimalism posits that brains in vats cannot have hallucinations as of white cups. 
Let's follow the common understanding of perceptual concepts as concepts that are of perceivable objects or property-instances. And let's assume for the sake of argument that any given perceptual concept is grounded in perception insofar as the existence of a perceptual concept depends on perceptions of the objects or property-instances that the concept is of. ${ }^{27}$ If this is right, then it follows that grounded minimalism holds globally: there cannot exist a perceptual concept that is not grounded in perception. It does not, however, follow from this that an individual subject must have had perceptions of the objects or property-instances that the concept is of to possess the relevant concept. So it does not follow that grounded minimalism holds locally. It follows only that there cannot exist perceptual concepts of objects or propertyinstances that have not been perceived by someone, somewhere. A subject can acquire a concept through testimony and thus possess a perceptual concept without having perceived any objects or propertyinstances that the concept picks out. If this is right, then any given individual perceiver can have hallucinations as of objects and propertyinstances that she has not perceived. It follows from this that ungrounded minimalism can hold locally, even if grounded minimalism holds globally. Moreover, it follows that there cannot be a world in which there are only brains in a vat that could have hallucinations as of white cups.

In light of these clarifications about the notion of concept, we can address the question of how minimalism can account for the possibility of hallucinations of uninstantiated properties while recognizing the Aristotelian principle. A hallucination of supersaturated red could be analyzed as a result of combining the concepts of red and saturatedness, thereby inducing an experience of a particularly saturated red. Alternatively, such a hallucination could be analyzed as a result of extrapolating from experiences of red with regular levels of saturatedness. ${ }^{28}$

By accepting that grounded minimalism holds globally, the defended view satisfies the Aristotelian principle. By accepting that ungrounded minimalism holds locally, the defended view allows that a subject can have hallucinations as of objects and property-instances unlike any she has seen. Finally, by accepting that the content of hallucination is derivative of the content of perception either insofar as it recombines the concepts acquired in past perceptions or insofar as the concepts

27 For a defense of this thesis, see Peacocke 1992 and Prinz 2002. This thesis is famously challenged by Fodor (1998).

28 It would lead too far afield to discuss the details of what it takes to extrapolate a concept here. For an excellent discussion, see Browne 2002. 
employed in hallucinations are extrapolations of concepts acquired in past perceptions, the defended view can allow for hallucinations of uninstantiated properties while satisfying the Aristotelian principle. ${ }^{29}$

I have argued that hallucinating subjects employ concepts that account for the intentional directedness to a seeming particular object and the properties that this object instantiates. But there is no need to think that employing such concepts entails the existence of the objects and property-instances that the concepts purport to pick out. Employing concepts necessitates only intensional awareness of the objects and property-instances that the concepts purport to pick out. It does not necessitate extensional awareness. A subject can employ a concept while failing to refer to the object or property-instance that the concepts purports to be of. If a hallucinating subject is not related to anything, then the concepts she employs remain empty.

As I have argued, possessing a concept grounds the ability to pick out the objects or property-instances that the concept is of. Therefore, the phenomenology that ensues from employing concepts is inherently related to the objects and property-instances that they pick out. So while minimalism analyzes phenomenology with appeal to concepts and thus abstract entities, these concepts are in turn analyzed in terms of perceptual relations to external, mind-independent objects and property-instances. By doing so, minimalism takes on board the naïve realist insight that being in a mental state with a certain phenomenology can be analyzed in terms of perceptual relations to external, mind-independent objects and properties. This insight demystifies what it means to be in a phenomenal state. Indeed, it paves the way for a naturalized view of the phenomenology of perceptual experience. ${ }^{30}$ However, by arguing that all there is to being in a mental state with a certain phenomenology is to be perceptually related to mind-independent objects or property-instances, naïve realists leave mysterious how one could be

Can Jackson's Mary have hallucinations of red? Mary is a color scientist who knows everything about colors but who lives in a black and white world and so has never seen any colors. So she could not have acquired the concept of red through perceptions of instances of red. If radical ungrounded minimalism holds locally, then Mary could have hallucinations of red. However, if one rejects the radical ungrounded view in favor of the modest ungrounded view, then it is plausible that perceptions of colors are necessary for a person to imagine what it would be like to experience red. So one might argue that some perceptions of colors other than red are necessary to have hallucinations of red. If this is right, then Mary could not have hallucinations of red, but her sister Anna could. Anna is a color scientist who knows everything about colors but who lives in a world with all the colors except red. So while she has seen all other colors, she has never seen red. For an excellent discussion of experiences of novel colors, see Macpherson 2003.

See in particular Fish 2009 for an account that brings out the naturalistic advantages of naïve realism. 
in a phenomenal state if one is not related to the very mind-independent objects or property-instances that one's phenomenal state purports to be of. ${ }^{31}$ By introducing concepts that ground our ability to refer to these external, mind-independent objects and properties, minimalism rejects the radical naïve realist thesis that all there is to being in a mental state with a certain phenomenology is to be related to mind-independent objects or property-instances. By rejecting the radical naïve realist thesis, the presented view constitutes a positive account of hallucinations on which subjectively indistinguishable hallucinations and perceptions share a common factor that grounds the phenomenology of the experiences.

So against disjunctivists, I have argued that perceptions and hallucinations share a common element that grounds the phenomenology of the experiences. However with disjunctivists, I have argued that hallucinations exhibit a deficiency that can only be explained with reference to accurate perceptions. Hallucinations are derivative of perceptions insofar as the concept employed in hallucinations can only be specified with reference to their possible roles in perceptions. I have argued that possessing concept grounds the ability to pick out its referent. Since concepts are analyzed in terms of perceptual relations to external, mind-independent objects and property-instances, minimalism not only satisfies the Aristotelian principle, it moreover amounts to a naturalized view of the phenomenology of experience.

In the next sections, I will elaborate on the notion of content that minimalism implies and will defend the view against possible objections. But first, it will be helpful to clarify how the suggested view can account for the difference between the phenomenology of experience and thought. This difference can be accounted for in a number of ways within the framework provided. I have assumed that there is a specific sensory mode in which concepts are employed when experiencing. ${ }^{32}$ One way to account for the difference between the phenomenology of experiencing a white cup and thinking about a white cup is with regard to differences in the mode in which the relevant concepts are employed. A second way of accounting for the difference is to argue that in contrast to thought, the content of experience is necessarily constituted at least in part by nonconceptual structures (e.g. Peacocke 1992, Tye 2000, Chalmers 2004). It is plausible that experiences differ from thoughts in both ways. If my argument holds at all, it holds regardless

\footnotetext{
31 For a defense of this radical naive realist thesis, see Campbell 2002, Brewer 2006, and Fish 2009. Martin (2004) argues for a more moderate version of naïve realism.

32 Among others, Crane (2003) and Chalmers (2004) argue that experience and thought differ with regard to modes or manners.
} 
of what stance one takes on these possible ways of accounting for the difference between the phenomenology of thought and experience.

The difference between the phenomenology of perception and thought has been accounted for in many other ways. A particularly influential one is to argue that there are qualia, sensations, or phenomenal properties present in experience but not in thought. Peacocke (1983, 2008) and Block (2003) among others argue that there are aspects of the phenomenology of experience-for instance blurriness and afterimages - that are not grounded in content. Accepting this idea would require modifying minimalism by arguing that only part of phenomenology is identified with employing concepts and anologous nonconceptual structures, namely only that part that purports to be of external, mind-independent objects and property-instances. Given this modification, accepting the existence of non-representational qualia, sensations, or phenomenal properties is compatible with minimalism - as long as the experiencing subject is not understood as standing in awareness relations to these sensations or phenomenal properties. But although compatible, I will show that the view presented undermines the need to appeal to such entities.

It is possible to account for phenomena such as blurriness and afterimages within an unrestricted representational framework (for defense, see Tye 2000 and Byrne 2001). This strategy is more in tune with the tenor of the argument presented here. Within the minimalist framework, a blurry experience of a white cup can be analyzed as being a matter of employing the concept of blurriness (among other concepts). The concept blurriness is grounded in perceptions of instances of blurriness. To give an example of a perception of an instance of blurriness: when I look out of the window on a rainy day, the tree in front of my window is presented blurrily to me because of the raindrops on the window. ${ }^{33}$ As I have argued, the subject who hallucinates blurriness need not herself have perceived instances of blurriness in the world. The concept could be acquired through testimony. So to ground the concept of blurriness in perception it is only necessary that someone has had perceptions of blurriness. Now, seeing something as blurry is of course distinct from seeing something blurrily, but the very same concept of blurriness can be understood to be employed in both experiences. The difference between seeing something as blurry and seeing something blurrily can be accounted for in virtue of what blurriness is attributed to. If one experiences an object as blurry, blurriness is attributed to that object. If one experiences blurrily, blurriness is attributed

33 For a detailed discussion of how such properties can be analyzed as mind-independent, external properties, see my 2008. 
to one's experience. In this way, minimalism undermines the need to appeal to qualia, sensations, or phenomenal properties to account for the phenomenology of perceptions and hallucinations. ${ }^{34}$

\section{The Relational Content of Perceptual Experience}

I have argued that hallucinating subjects employ the same concepts and nonconceptual structures that they employ to refer to objects and property-instances when perceiving. Since a hallucinating subject does not stand in an awareness relation to objects or property-instances, the concepts she employs remain empty. How should one think about the content that ensues from employing concepts and nonconceptual structures? In this section, I will specify the implications of ontological minimalism on the content of experience.

The thesis that content ensues from employing concepts that pick out objects and property-instances implies that the content of experience is both inherently relational and Fregean. ${ }^{35}$ What does it mean for content to be inherently relational? If the content of experience ensues from employing concepts and possessing a concept is a matter of being able to pick out its referent, then relations to objects and propertyinstances are implicated in the very nature of experiential content. Moreover, if the fact that concepts pick out objects and propertyinstances in some situations and not in others has any semantic significance, then the content ensuing from employing these concepts will depend at least in part on the situation in which they are employed. Another way of expressing the same idea is to say that the accuracy condition of experiential content depends for the particular objects and property-instances to which the subject is related and not just on the way in which the subject experiences the objects and properties. A content is inherently relational if and only if it depends at least in part on the mind-independent objects and property-instances that the content is

$34 \quad$ There are ways of understanding qualia on which they are simply identified with the phenomenology of experience, such that any phenomenological state necessarily instantiates qualia. This understanding of qualia implies that experiences trivially instantiate qualia. But if that is all that is meant with qualia, then introducing qualia just amounts to a reformulation of the fact that experiences are phenomenological states. For a discussion of this set of issues, see Stoljar 2004.

It should be noted that it has been argued that if inverted spectrum scenarios are empirically possible, then introducing qualia is necessary, where qualia are understood as more substantive than simply what can be identified with the phenomenology of experience (Shoemaker 1982). However, as Egan (2006) has argued convincingly, it can be ruled out on conceptual grounds that inverted spectrum scenarios are empirically possible.

For a detailed development of this way of understanding the content of perception, see my 2010. 
of. We can call a content that is inherently relational in the sense articulated a relational content.

Relational contents differ depending on what object or propertyinstance (if any) the subject is related to. So the token content covaries with the environment of the experiencing subject. In the case of an accurate perception, the token content determines a referent. Insofar as the token relational content is individuated in part by the object or property-instance, which it determines, it is at least in part dependent on the environment of the experiencing subject. Another way of expressing the same idea is to say that relational contents are mental indexicals. A content determines the contextual relation that something must bear to a mental state to be the referent of that mental state.

How should we understand the Fregean nature of these relational contents? If perceptual content is inherently relational as argued, then it must be understood as constituted by de re modes of presentations rather than de dicto modes of presentations. Were perceptual content constituted by de dicto modes of presentations, then a two-stage view of determining reference would be implied. On such a two-stage view, we first represent a non-relational content, and in a second step we refer to external object and properties on the basis of this content. ${ }^{36}$ The mental act of representing a de dicto mode of presentation is independent of the second step in which an external particular may be determined. Such a two-stage view faces the problem of how the content grounds the ability to refer to external particulars. This problem is avoided, if perceptual content is understood to be constituted by de re rather than de dicto modes of presentation. The introduction of de re modes of presentation is motivated by recognizing that modes of presentation play a dual role: they have a specific cognitive significance and they pick out or refer to objects and property-instances. If the role of modes of presentation as picking out objects and property-instances is taken seriously, then the mental state of a subject who successfully picks out the object or property-instance at which she is intentionally directed will arguably not be the same as the mental state of a subject who fails to refer to the object or property-instance at which she is intentionally directed. ${ }^{37}$ But a descriptive, de dicto mode of presentation is not affected if there is no referent. By contrast to de dicto modes of presentation, de re modes of presentation are inherently relational in

36 For an argument against such a two-stage view of determining the reference, see Johnston 2004, p. 150f. Johnston does not distinguish between de dicto and de re modes of presentation, and as a consequence sees the problem articulated in the main text as a problem for any Fregean view tout court. As I will show it is only a problem for a view on which Fregean senses are de dicto rather than de re.

For a defense of this thesis, see my forthcoming-b. 
that what object or property-instance (if any) the subject is related to makes a constitutive difference to the nature of the content. So de re modes of presentation constitutively depend on the objects or propertyinstances that they pick out.

There are at least two ways of understanding relational contents and consequently two ways of understanding de re modes of presentation. On one view, a subject can only have an experience with content if she is related to the very object that her experience purports to be of. Such a view is motivated by a particular understanding of what it means to represent an object: only if a subject is related to an object, can an object be presented to her such that she could be representing the object. On the basis of this way of understanding what it means to represent an object, the conclusion is drawn that a hallucinating subject is not in a mental state with content, it only seems to her that she is representing. There is only an illusion of content. ${ }^{38}$ So this view has it that perceptual content is radically object-dependent. The problem with this way of understanding perceptual content is that it downplays the cognitive significance of modes of presentation. When a subject hallucinates, the way things seem to her plays a certain cognitive role. If it seems to her that she is perceptually related to a white cup, she may for example reach out and try to pick up the cup. By denying that hallucinating subjects are in representational states, this state of affairs is not explained. It is not clear how the illusion of content could motivate the subject to act. Moreover, a view on which perceptual content is radically object-dependent amounts to a disjunctivist view of experience and faces the problems of such a view.

These problems are avoided, if relational contents are understood not as radically object-dependent, but rather as partly object-dependent or, more generally, as partly dependent on the environment of the experiencing subject. ${ }^{39}$ I will call these contents potentially gappy Fregean contents. Given that a hallucinating subject employs the very same concepts as she would be employing were she successfully perceptually related to objects and property-instances, there is no reason to think that she is not in a mental state with content. Indeed, we can understand the content of any two subjectively indistinguishable experiences $e_{1}$ and $e_{2}$ in which a subject $s$ is perceptually related to the same object dependent. The understanding of experiential content developed here turns out to partly parallel their work as well as the work of so-called latitudinarians, according to which de re attitudes (or contents) are a special case of de dicto attitudes (or contents); see in particular Sosa 1970, 1995 and Jeshion 2002.
} 
$o$ in the same way as including $\operatorname{MOP}_{r}(o)$, where $\operatorname{MOP}_{r}(o)$ is the output of a concept that takes objects as inputs. A hallucination that is subjectively indistinguishable from $e_{1}$ is a matter of employing the same concept, but since there is no object present the concept remains empty: $M O P_{r}\left(\_\right)$, where $M O P_{\mathrm{r}}(\ldots)$ is an empty concept. Modes of presentation of property-instances can be specified in an analogous way. So if I perceive a white cup $o$, the content of my perception will be

$$
<\mathrm{MOP}_{\mathrm{r}}(\mathrm{o}), \mathrm{MOP}_{\mathrm{r}}(\mathrm{P})>
$$

where $\operatorname{MOP}_{r}(o)$ is a de re mode of presentation of the cup $o$ and $M_{O P}(P)$ is a mode of presentation of the property that this object instantiates. If I hallucinate a white cup and thus am not related to any white cup, the content of my hallucination will be

$$
<\mathrm{MOP}^{1}{ }_{\mathrm{r}}\left(\_\right), \mathrm{MOP}^{2}{ }_{\mathrm{r}}\left(\_\right)>
$$

where $\mathrm{MOP}_{r}{ }_{r}\left({ }_{-}\right)$in the object-place is an empty object-concept and $M O P_{r}{ }_{r}$ __ ) in the property place is an empty property-concept. ${ }^{40}$ The empty concept in the object-place specifies the kind of object that has to be present for the experience to be accurate. It accounts for the intentional directedness of the experience to a (seeming) particular object. The empty concept in the property-place specifies the properties that this object would instantiate, if the experience were accurate. Since the hallucinating subject is not related to the object or propertyinstances that the concepts employed purport to pick out, the modes of presentation are gappy. The gap marks that there is a reference failure.

Although token modes of presentation covary with the situation in which the subject experiences, the mode of presentation types remain the same across subjectively indistinguishable experiences. The content of a hallucination is a token of the same type of de re mode of presentation as the token content of a subjectively indistinguishable perception. The modes of presentation types just are the concepts employed. Insofar as an experiencing subject can employ a concept even if she is not in an environment that contains the object or property-instance that the concept purports to pick out, employing concepts is independent of objects and property-instances. As a consequence, subjectively indistinguishable experiences share a content element (namely mode of presentation types) that is independent of objects and propertyinstances. As I have shown, environment-dependence is not an essential my 2006. 
feature of potentially gappy Fregean contents. Although a part of the content of an experience of a white cup is dependent on the environment in the case of a perception, the very same type of de re mode of presentation can be tokened if no white cup is present. The token content of a hallucination of a white cup is naturally not dependent on their being a white cup in the environment of the hallucinating subject.

\section{The Metaphysics of Experience-Objections and Replies}

I have developed a view of the common factor between subjectively indistinguishable perceptions and hallucinations that avoids analyzing experiences as involving awareness relations to abstract entities, sensedata, or any other peculiar entities.

\section{Objection 1.}

One could object that concepts are abstract entities: the thesis that experiencing subjects employ concepts implies that they are related to these concepts.

\section{Response.}

My aim was not to avoid all reference to abstract entities, nor was my aim to argue against all versions of the thesis that subjects are related to abstract entities. My aim was rather to argue against the thesis that experiencing subjects stand in awareness relations to abstract entities or any other peculiar entities. Moreover, my aim was to vindicate the Aristotelian principle and thus understand abstract entities or any other types in terms of their instances. As I will show, the suggested view does not entail that experiencing subjects stand in awareness relations to concepts and it vindicates the Aristotelian principle.

One can quantify over concepts, therefore they must exist. Although they exist, they are not extended and do not have a spatiotemporal location. Moreover, they do not enter into causal interactions without being employed in mental states. Since they do not have spatiotemporal locations and do not enter into causal interactions, they must be abstract. While concepts are abstract entities, minimalism does not imply that experiencing subjects stand in awareness or acquaintance relations to concepts. More specifically, minimalism does not explain phenomenology in terms awareness or acquaintance relations to concepts or any other abstract entities. I have argued rather that the phenomenology of experience can be identified with employing concepts and nonconceptual structures in a sensory mode. There is no reason to think that this employment relation amounts to an awareness relation. 
Moreover on the view developed, concepts are analyzed in terms of perceptual relations to the very external mind-independent objects or property-instances that the concepts are of and that we are aware of when we accurately perceive. As a consequence, the Aristotelian principle is vindicated. When we accurately perceive a white cup, we employ concepts that pick out the very object and property-instances to which we are perceptually related. When we hallucinate, we employ the very same concepts that are grounded in such accurate perceptions.

\section{Objection 2.}

One could object that a content is an abstract entity: the thesis that perceptual experiences have content implies that experiencing subjects stand in an awareness relation to that content.

\section{Response.}

In order to respond to this objection, it will be helpful to distinguish between three ways in which one might say that experiences have content. On one view, the thesis that experience has content is analyzed in terms of the thesis that the experiencing subject stands in an awareness relation to the content or its constituents, such that this awareness relation grounds the phenomenology of the experience. Call this the content awareness view. This view goes back to Russell (1913), who argued that an experiencing subject stands in acquaintance relations to the constituents of the proposition that characterizes her experience. In the tradition of Russell, some views according to which experience is a propositional attitude to a content are formulated in a way that implies a content awareness view. However as noted earlier, many who hold that the content of experience is a Russellian proposition analyze experience in terms of a propositional attitude to a content without that propositional attitude constituting an awareness relation to that content or its constituents (e.g. Byrne 2001, Pautz 2007).

A very different way of understanding what it means to say that experiences have content is to say that every experience can be associated with a content that describes what the subject is aware of, without that content being a proper part of the experience. Call this the associated content view. This view entails only that every mental event can be described by articulating a sentence that has a certain content. Articulating what contents can be associated with an experience is informative, but the view that such contents can be articulated does not entail that the experiences have content in any substantive sense of "have".

In between these two poles is a view according to which experience has content without the subject standing in an awareness relation to 
that content. The idea is that in virtue of being perceptually related to an object or a property-instance, one represents that very object or property-instance by employing concepts that pick out the relevant object or property-instance. The content of the experience ensues from employing concepts. So far there is no need to say that one stands in an awareness relation to the content. What happens in the case of a hallucination? One employs the very same concepts employed in perception without being perceptually related to objects or propertyinstances. As in the perceptual case, there is no need to say that one stands in an awareness relation to the content. Rather one employs concepts in virtue of which one is intentionally directed at what seems to one to be an object or a property-instance. In this sense, the thesis that experience has content does not entail that one stands in an awareness relation to that content.

\section{Objection 3.}

It could be argued that the property-cluster theorist can analyze hallucinations of properties such as supersaturated red in a way analogous to the suggested view, thereby avoiding the metaphysical problems that I have argued a property-cluster theorist faces. According to minimalism, a hallucination of supersaturated red could be analyzed as a result of jointly employing the concepts of red and saturatedness, thereby inducing an experience of a particularly saturated red. Alternatively, a hallucination of supersaturated red could be analyzed as a result of extrapolating from experiences of red with regular levels of saturatedness. The property-cluster theorist could argue that supersaturated red is a complex property and posit that while supersaturated red is uninstantiated, the properties that the cluster consists of are instantiated. So hallucinations of supersaturated red can be analyzed in terms of (awareness) relations to instantiated properties. ${ }^{41}$

\section{Response.}

While hallucinating a unicorn may be analyzable in terms of standing in an awareness relation to an uninstantiated property-cluster that consists of the instantiated properties of being white, having a single horn, and being horse-shaped etc., it is more contentious that hallucinating supersaturated red can be in analyzed in terms of standing in an awareness relation to the uninstantiated complex property that consists of the instantiated properties of redness and saturatedness. It is plausible that all color properties are phenomenologically basic and that therefore

$41 \quad$ This objection is due to Adam Pautz. 
they cannot be analyzed in terms of more basic color properties. However, if uninstantiated color properties can be analyzed as composites of instantiated color properties, then the metaphysical problem would indeed be avoided. Nonetheless, the phenomenological problem remains. A subject who suffers a non-veridical hallucination as of a cat by definition does not stand in an awareness relation to a material, mind-independent cat or any properties it instantiates. Since the properties that hallucinating subjects are said to be aware of are not instantiated where they seem to be instantiated, the revised version of the property-cluster view analyzes the phenomenology of hallucinations in terms of awareness relations to universals. Given that universals are not spatially extended it is unclear how one can be sensorily aware of universals.

As I showed in my response to the previous two objections, minimalism does not require any commitment to the thesis that hallucinating subject stand in an awareness relations to abstract entities. Moreover, in contrast to the property-cluster view, minimalism is not commited to positing the existence of uninstantiated universals. Finally, in contrast to the revised property-cluster view, minimalism is not committed to the contentious thesis that uninstantiated color properties can be analyzed as composites of instantiated color properties.

\section{Objection 4.}

One could argue that if a property-cluster theorist accepts the distinction between intensional and extensional awareness, then she could hold that hallucinating subjects are intensionally aware of properties. Since intensional awareness relations do not require the existence of the properties which one is aware of, such a view avoids the metaphysical problems that I have argued a property-cluster theorist faces. ${ }^{42}$

\section{Response.}

Let's assume for the sake of argument that this strategy would indeed avoid the metaphysical problem. The problem with such a modified property-cluster view is that it is unclear how it would amount to an explanation of the phenomenology of experience. The property-cluster view answers the hallucination question by arguing that hallucinating subjects stand in awareness relations to (uninstantiated) property-clusters. If these property-clusters are now considered to be not only potentially uninstantiated but moreover non-existing it is unclear how

42 Thanks to Fred Dretske for pressing me on this point. 
appealing to them could explain the phenomenological nature of hallucinations and more generally perceptual experiences.

\section{Objection 5.}

A third way in which the property-cluster theorist could aim to circumvent the metaphysical problem is to argue that supersaturated red is instantiated, namely by the mental state of a subject who suffers a hallucination of supersaturated red. ${ }^{43}$

\section{Response.}

While such an analysis would avoid the metaphysical problem of having to accept the existence of uninstantiated universals, it would amount to one of the following two undesirable views. On one view, the phenomenology of hallucination is identified with the properties (e.g. phenomenal properties) that the mental state is stipulated to be constituted of. Arguably, such an approach would fail to give a noncircular explanation of what accounts for the phenomenology of the hallucination, since the phenomenology is now explained in terms of properties of the mental state, the nature of which is the explanandum. ${ }^{44}$ In this sense, such an approach simply reformulates the fact that experiences are phenomenological states. On a second view, phenomenology is explained in terms of awareness or acquaintance relations to concrete, mind-dependent entities, such as phenomenal properties, sense-data, qualia, or Meinongian objects. This approach is just a version of the peculiar entity view. The peculiar entities in question are not abstract entities, but rather concrete, mind-dependent entities. $^{45}$

The aim of the paper was to explain phenomenology without having to appeal to awareness relations to any entities other than the very mind-independent objects and property-instances that the experiencing subject is aware of. On the view I have suggested, phenomenology is identified with employing concepts or analogous nonconceptual structures in a sensory mode. Concepts are in turn understood in terms of perceptual relations to the very mind-independent objects or propertyinstances that the concepts are of. While concepts are analyzed in terms of such perceptual relations, they can be employed in environments where the relevant objects or property-instances are not in fact present.

\footnotetext{
43 Thanks to Adam Pautz for a helpful email exchange on this set of issues.

44 It could be stipulated that these properties are in fact very different than the explanandum, but such a stipulation would be at best ad hoc. 
I take such an account to give an adequate, naturalized explanation of phenomenology.

\section{Conclusion}

I have developed a way of analyzing the phenomenology of experience that does not require positing that hallucinating subjects stand in awareness relations to abstract entities or any other peculiar entities. I have argued that a hallucinating subject does not stand in an awareness relation to anything despite enjoying a phenomenology that purports to be of material mind-independent objects and property-instances. Defending the conjunction of these two theses required distinguishing between extensional and intensional awareness. As I argued, hallucinating subjects are not extensionally aware, but rather intensionally aware. Recognizing this distinction cleared the path for a view on which hallucinations have content, where this content has the same logical form as the content of a subjectively indistinguishable perception. The concepts and nonconceptual structures employed in hallucinations are the very same as the ones that pick out objects and property-instances in perceptions. So in contrast to disjunctivism, minimalism posits that perceptions and hallucinations share a common element. The concepts and nonconceptual structures that a hallucinating subject employs account for the intentional directedness to seeming objects and propertyinstances. Since the subject fails to refer to any objects or propertyinstances, the concepts remain empty. Since the concepts remain empty, the content of a hallucination is defective. As I argued, a hallucinating subject only possesses concepts because she has the ability to refer to the objects and property-instances that the concept is of. Since the concepts employed in hallucinations can only be specified with reference to their possible roles in perceptions, hallucinations exhibit a deficiency that can only be explained with reference to accurate perceptions.

So minimalism reconciles the following four theses. First, there is a proper common element between subjectively indistinguishable perceptions and hallucinations that grounds the phenomenology of the experiences, thereby satisfying the indistinguishability desideratum. In this respect, the view is an improvement over disjunctivism and naïve realism, that is, views according to which perceptions and hallucinations do not share a common element. Second, the view does not require positing that hallucinating or perceiving subjects stand in an awareness relation to peculiar entities. In this respect, the view is ontologically more minimalist than any view that must appeal to such entities. While concepts are abstract entities, we do not stand in awareness relations to concepts when we employ concepts. Moreover, on the notion of 
concepts in play, there cannot be a perceptual concept that has not been employed to refer to the very mind-independent objects or property-instances that the concept is of. Third, the view satisfies the Aristotelian principle according to which the existence of any type depends on its tokens that in turn depend on concrete entities of the physical world. In this respect, the view is at an advantage over any view that must assume a Platonic 'two realms'-view. Finally, the view accounts for the phenomenology of perceptions and hallucinations in terms of relations to external, mind-independent objects and property-instances. Thereby, it amounts to a naturalized view of the phenomenology of experience. ${ }^{46}$

\section{References}

Armstrong, D. 1989. Universals: An Opinionated Introduction. Boulder, CO: Westview Press.

Bach, K.1987/1994. Thought and Reference. Oxford: Oxford University Press (revised with postscript 1994).

— 2007. "Searle Against the World: How Can Experiences find their Objects?" John Searle's Philosophy of Language, ed. S. L. Tsohatzidis. Cambridge: Cambridge University Press.

Block, N. 1986. "Advertisement for a Semantics for Psychology." Midwest Studies in Philosophy 10: 615-78.

1990. "Inverted Earth." Philosophical Perspectives 4, ed. J. Tomberlin. Northridge: Ridgeview Publishing Company.

2003. "Mental Paint." Reflections and Replies: Essays on the Philosophy of Tyler Burge, ed. M. Hahn and B. Ramberg. Cambridge, MA: MIT Press.

Brandom, R. 1994. Making It Explicit. Cambridge, MA: Harvard University Press.

Brewer, B. 2006. "Perception and Content." The European Journal of Philosophy 14: 165-81.

Browne, A. 2002. Representation and Extrapolation in Multilayer Perceptions. Cambridge, MA: MIT Press.

Burge, T. 1979. "Individualism and the Mental." Midwest Studies in Philosophy 4: 73-121.

46 I am grateful to David Chalmers, Fred Dretske, Ole Koksvik, Fiona Macpherson, Jonathan Schaffer, Laura Schroeter, Nico Silins, and particularly Adam Pautz for detailed written comments on a draft of this paper. Thanks also to Kent Bach, Bill Fish, Frank Jackson, Susanna Siegel, Declan Smithies, Daniel Stoljar, and Brad Thompson for comments and discussions as well as to the audiences at the Hallucination on Crete conference, the Australasian Assocation for Philosophy 2008 meeting, and the Themes from Crispin Wright workshop. 
Byrne, A. 2001. "Intentionalism Defended." The Philosophical Review 110: 199-240.

Campbell, J. 2002. Reference and Consciousness. Oxford: Oxford University Press.

2009. "Consciousness and Reference." Oxford Handbook of Philosophy of Mind, ed. B. McLaughlin and A. Beckermann. Oxford: Oxford University Press.

Carr, D. 1979. "The Logic of Knowing How and Ability." Mind 88: 394-409.

Carruthers, P. 2000. Phenomenal Consciousness: A Naturalistic Theory. Cambridge: Cambridge University Press.

Chalmers, D. 1996. The Conscious Mind. Oxford: Oxford University Press.

2004. "The Representational Character of Experience." The Future for Philosophy, ed. B. Leiter. Oxford: Oxford University Press.

Chisholm R. 1957. Perceiving: A Philosophical Study. Ithaca: Cornell University Press.

Crane, T. 1998. "Intentionality as the Mark of the Mental." Contemporary Issues in the Philosophy of Mind, ed. A. O'Hear. Cambridge: Cambridge University Press.

— 2003. "The Intentional Structure of Consciousness." Consciousness: New Philosophical Perspectives, ed. A. Jokic and Q. Smith. Oxford: Oxford University Press.

2006. "Is there a Perceptual Relation?" Perceptual Experience, ed. T. Gendler and J. Hawthorne. Oxford: Oxford University Press.

Davies, M. 1992. "Perceptual Content and Local Supervenience." Proceedings of the Aristotelian Society 92: 21-45.

Devitt, M. 1981. Designation. New York: Columbia University Press.

Dretske, F. 2000. "The Mind's Awareness of Itself." Perception, Knowledge, and Belief. Cambridge: Cambridge University Press.

Dummett, M. 1993. "What is a Theory of Meaning?" The Seas of Language. Oxford: Oxford University Press.

Egan, A. 2006. "Appearance Properties?" Nô̂s 40: 495-521.

Evans, G. 1982. The Varieties of Reference, ed. J. McDowell. Oxford: Oxford University Press.

Fish, W. 2009. Perception, Hallucination, and Illusion. New York: Oxford University Press.

Fodor, J. 1975. The Language of Thought. Cambridge, MA: Harvard University Press.

1998. Concepts: Where Cognitive Science Went Wrong. New York: Oxford University Press. 
Ffytche, D. H. 2008. "The Hodology of Hallucinations." Cortex 44: 1067-1083.

Ffytche, D. H. and Howard, R. J. 1999. "The Perceptual Consequences of Visual Loss: 'Postive' pathologies of Vision." Brain 122: 1247-60.

Frege, G. 1879. Begriffsschrift: eine der arithmetischen nachgebildete Formelsprache des reinen Denkens. Halle: L. Nebert.

Haddock, A. and Macpherson, F. 2008. "Introduction: Varieties of Disjunctivism." in their Disjunctivism: Perception, Action, Knowledge. Oxford: Oxford University Press.

Harman, G. 1987. "(Non-solipsistic) Conceptual Role Semantics." New Directions in Semantics, ed. E. Lepore. London: Academic Press.

— 1990. "The Intrinsic Quality of Experience." Philosophical Perspectives 4, ed. J. Tomberlin. Northridge: Ridgeview Publishing Company.

Heck, R. 2000. "Nonconceptual Content and the 'Space of Reasons'." The Philosophical Review 109: 483-523.

Hornsby, J. 2004. "Semantic Knowledge and Practical Knowledge." Supplement to the Proceedings of the Aristotelian Society 79: 10730.

Hinton, J. M. 1973. Experiences. Oxford: Oxford University Press.

Jackendoff, R. 1987. Computation and Cognition. Cambridge, MA: MIT Press.

Jackson, F. 1977. Perception: A Representative Theory. Cambridge: Cambridge University Press.

Jeshion, R. 2002. "Acquaintanceless De Re Belief." Meaning and Truth, ed. J Campbell, M. O'Rourke and D. Shier. New York: Seven Bridges Press.

Johnston, M. 2004. "The Obscure Object of Hallucination." Philosophical Studies 120: 113-83.

Kripke, S.1972/1980. Naming and Necessity. Cambridge, MA: Harvard University Press.

Laurence, S. and Margolis, E. 1999. "Concepts and Cognitive Science." Concepts: Core Readings, ed. E. Margolis and S. Laurence. Cambridge, MA: MIT Press.

Lycan, W. G. 1996. Consciousness and Experience. Cambridge, MA: MIT Press.

MacPherson, F. 2003. "Novel Colors and the Content of Experience." Pacific Philosophical Quarterly 84: 43-66.

Martin, M. G. F. 2002. 'The Transparency of Experience'. Mind and Language 17: 376-425.

— 2004. "The Limits of Self-Awareness." Philosophical Studies 103: $37-89$. 
McDowell, J. 1984. "De Re Senses." The Philosophical Quarterly 34: 283-94.

McGinn, C. 1982. The Character of Mind. Oxford: Oxford University Press.

McLaughlin, B. 1996. "Lewis on What Distinguishes Perception From Hallucination." Problems in Perception, ed. K. Akins. Oxford: Oxford University Press.

_ 2007. "Type Materialism for Phenomenal Consciousness." Blackwell Companion to Consciousness, ed. M. Velmans and S. Schneider. Oxford: Blackwell Publishing.

Moore, G. E. 1953. Some Main Problems of Philosophy. London: George, Allen and Unwin.

Parsons, T. 1980. Nonexistent Objects. New Haven: Yale University Press.

Pautz, A. 2007. "Intentionalism and Perceptual Presence." Philosophical Perspectives 21, ed. J. Hawthorne. Northridge: Ridgeview Publishing Company.

forthcoming. "The Intentional Structure of Visual Experience." Perceiving the World, ed. B. Nanay. Oxford: Oxford University Press.

Peacocke, C. 1981. "Demonstrative Thought and Psychological Explanation." Synthese 49: 187-217.

1983. Sense and Content: Experience, Thought, and Their Relations. Oxford: Oxford University Press. 1992. A Study of Concepts. Cambridge, MA: MIT Press.

2008. "Sensational Properties: Theses to Accept and Theses to Reject." Revue Internationale de Philosophie 62: 7-24.

Perry, J. 1977. "Frege on Demonstratives." The Philosophical Review 86: 474-97.

Price, H. H. 1950. Perception. London: Methuen.

Prinz, J. 2002. Furnishing the Mind: Concepts and their Perceptual Basis. Cambridge, MA: MIT Press.

Putnam, H. 1975. "The Meaning of Meaning." Reprinted in his Philosophical Papers vol. 2: Mind, Language, and Reality. Cambridge: Cambridge University Press.

Recanati, F. 1993. Direct Reference: From Language to Thought. London: Blackwell.

Robinson, H. 1994. Perception. London: Routledge.

Rosch, E. 1978. "Principles of Categorization." Cognition and Categorization, ed. E. Rosch and B. Lloyd. Hillsdale, NJ: Lawrence Erlbaum Associates.

Russell, B. 1913. Theory of Knowledge: London: Routledge 1992. 
Ryle, G. 1949. The Concept of Mind. Chicago: University of Chicago Press.

Schellenberg, S. 2006: Perception in Perspective. Doctoral Dissertation. University of Pittsburgh.

— 2008. "The Situation-Dependency of Perception." The Journal of Philosophy 105: 55-84.

2010. "The Particularity and Phenomenology of Perceptual Experience." Philosophical Studies.

forthcoming-a. "Perceptual Content Defended." Noûs.

— forthcoming-b. "Externalism and the Gappy Content of Hallucination." Hallucination, ed. F. E. Macpherson and D. Platchais, MIT Press.

Sellars, W. 1963. Science, Perception and Reality. Atascadero, CA: Ridgeview Publishing Company.

Shoemaker, S. 1982. "The Inverted Spectrum." The Journal of Philosophy 79: 357-381.

— 2007. "A Case for Qualia." Contemporary Debates in Philosophy of Mind, ed. B. McLaughlin and J. Cohen. London: Blackwell.

Siegel, S. 2004. "Indiscriminability and the Phenomenal." Philosophical Studies 120: 91-112.

— 2008 "The Epistemic Conception of Hallucination." Disjunctivism: Perception, Action and Knowledge, ed. F. Macpherson. Oxford: Oxford University Press.

Smith, A. D. 2002. The Problem of Perception. Cambridge, MA: Harvard University Press.

Smith, E. and Medin, D. 1981. Categories and Concepts. Cambridge, MA: Harvard University Press.

Snowdon, P. 1981. "Perception, Vision and Causation." Proceedings of the Aristotelian Society 81: 175-92.

Sosa, E. 1970. "Propositional attitudes de dicto and de re." The Journal of Philosophy 67: 883-96.

1993. “Abilities, Concepts, and Externalism." Mental Causation, ed. J. Heil and A. Mele. Oxford: Oxford University Press.

1995. "Fregean Reference Defended" and "More on Fregean Reference." Philosophical Issues 6: 91-99; 113-22.

Stanley, J. and Williamson, T. 2001. "Knowing How." The Journal of Philosophy 98: 411-44.

Stoljar, D. 2004. "The Argument from Diaphanousness." New Essays in the Philosophy of Language and Mind. Supplemental volume of The Canadian Journal of Philosophy, ed. M. Ezcurdia, R. Stainton and C. Viger. Calgary: University of Calgary Press.

Strawson, P.F. 1979. "Perception and its Objects." Perception and Identity, ed. G. F. MacDonald. London: Macmillian. 
Travis, C. 2004. "Silence of the Senses." Mind 113: 57-94.

Tye, M. 2000. Consciousness, Color and Content. Cambridge, MA: MIT Press.

2002. "Representationalism and the Transparency of Experience." Noûs 36: 137-51.

_ 2007. "Intentionalism and the Argument from no Common Content." Philosophical Perspectives 21, ed. J. Hawthorne. Northridge: Ridgeview Publishing Company.

Williams, D. C. 1953. "The Elements of Being." Review of Metaphysics 7: 3-18; 171-92.

Williamson, T. 1990. Identity and Discrimination. Oxford: Blackwell. 